\title{
Intelligent Approaches for Smart Cities
}

Prof. Dr.-Ing. habil. Dr.h.c. Uranchimeg Tudevdagva ${ }^{1}$ and Dr. Ariane Heller

Call for submission. The Embedded Self-Organizing System Journal (ESSJ) is calling for contributions to an issue on the subject of "Smart Cities". This issue focuses on the wide variety of application areas for the sustainable development of smart cities.

For this journal, we choose a modern kind of electronic publication, which provides a flexible way to discuss latest research results. The advantages of such an e-journal are multifarious. Compaired to traditional paper journals, we replace the classic review process with an online review mode. Each issue starts with an initial editorial and an official call for papers. The submitted articles will be reviewed and, if accepted, published as soon as the final version is submitted by authors to ESSJ. Based on this process, each open issue can be filled successive until the certain number of articles is reached. During this period, all accepted papers are published online while other papers are still in the reviewing process. Accordingly, the publication time is reduced to a minimum. In addition, multiple issues with different focus can co-exist at the same time, which provides completely new possibilities to react on latest research topics. The journal allows also the integration of discussions and other reactions on published articles in the same journal issue. Finally, we are looking for fresh ideas and novel scientific works.

\section{Intelligent Approaches for Smart Cities}

Due to the rapid development of technologies many countries have ideas to establish smart cities based on high technologies where technologies should support citizen friendly and secure environment for sustainable city life.

Several European universities together with universities from Kazakhstan, Mongolia, and Russia are working on joint project: SMRTCITY - "Innovative Approach towards a Master Program on Smart Cities Technologies". Main aim of this project is to develop a double Degree Master Program with focus on technologies for smart cities. The duration of the project is 3 years, between 2018 and 2021, it was started in 2018. During project time in a pilot phase, the students from the partner universities from Kazakhstan, Mongolia and Russia study at European universities in Riga, Athens and Chemnitz.

The coordinator of the project is the Technical University of Sofia (TUS), Bulgaria, partner universities are: International Hellenic University (IHU), Greece (former Alexander Technological Educational Institute of Thessaloniki (ATEITH), Chemnitz University of Technology (TUC), Germany, Rigas Tehniska Universitate (RTU), Latvia, Asociatia Pentru Tehnologia Informatiei Si Comunicatii Din Rom (ATIC), Romania, Yuri Gagarin State Technical University of Saratov (SSTU), Novosibirsk State Technical University (NSTU), The Russian Union of CIOs (RUCIO), National University of Mongolia (NUM), Mongolian University of Science and Technology (MUST), Intec LLC (INTEC), Al-Farabi Kazakh National University (KazNU), L.N. Gumilyov Eurasian National University (ENU), Kazakhstan Association for Engineering Education (KAZSEE). The current issue of our e-journal invites all types of

Assoc. Prof. Dr.-Ing. habil. Dr.h.c. Uranchimeg Tudevdagva

Chemnitz University of Technology, Germany

Researcher of Computer Engineering Department

Professor of Power Engineering School

Mongolian University of Science and Technology

E-mail: uranchimeg.tudevdagva@informatik.tu-chemnitz.de uranchimeg@must.edu.mn 


\section{Embedded Self-organizing Systems}

contributions related to the application of embedded systems in technologies for smart cities.

Submission period: Opening March 2021 and Closing December 2021.

The paper should be at least 4 pages up to 8 pages. 